\title{
Pengaruh Variasi Ketinggian Reservoir Terhadap Daya Turbin Air Impuls Dengan Sudu Bolak-Balik
}

\author{
Kristomus Boimau ${ }^{1)}$, Nurhayati' ${ }^{2}$, Rima N. Selan ${ }^{3)}$, Andi Prasetyo ${ }^{4)}$ \\ 1,2,3,4) Jurusan Teknik Mesin, Universitas Nusa Cendana \\ E-mail: ${ }^{1}$ kristomus.boimau@ @ staf.undana.ac.id, ${ }^{2)}$ nurhayati.nur@ staf.undana.ac.id, \\ ${ }^{3)}$ rima_selan@staf.undana.ac.id
}

\begin{abstract}
Abstrak
Air adalah salah satu Sumber Daya Alam (SDA) yang dapat dimanfaatkan energinya, sehingga dari semula hanya memiliki energi potensial dapat diubah menjadi energi kinetik, dimana energi kinetik tersebut dapat dimanfaatkan menjadi energi mekanis pada sistem kerja turbin, dan kondisi debit air sangat mempengaruhi daya turbin, oleh karena itu penelitian ini memvariasikan ketinggian reservoir untuk merubah besar debit air dan mengamati pengaruhnya terhadap daya turbin air impuls dengan sudu bolak-balik. Reservoir yang digunakan dalam penelitian ini memiliki volume $0,2 \mathrm{~m}^{3}$, dan diameter saluran keluarnya adalah $0,055 \mathrm{~m}$, sedangkan turbin airnya memiliki diameter $0,18 \mathrm{~m}$ dengan jenis impuls yang sudunya bolak-balik. Pada ketinggian reservoir $0 \mathrm{~m}$, debit airnya adalah $0,008 \mathrm{~m}^{3} / \mathrm{s}$ dan menghasilkan daya sebesar $37,040 \mathrm{~W}$, sedangkan saat ketinggian reservoir dinaikkan pada $0,40 \mathrm{~m}$ daya yang dihasilkan turbin juga semakin meningkat menjadi 92,236 W. Ketika tinggi reservoir dinaikkan hingga $0,89 \mathrm{~m}$, daya turbin adalah $192,987 \mathrm{~W}$, kondisi ini menunjukkan bahwa tinggi reservoir berbanding lurus dengan daya turbin, sehingga jika reservoir semakin tinggi maka daya turbin juga semakin bertambah.
\end{abstract}

Kata kunci: daya, debit, impuls, reservoir

\section{Abstract}

Water is one of the natural resources that can be utilized for energy, starting with potential energy can be converted into kinetic energy, where the kinetic energy can be utilized as mechanical energy in the turbine work system, and the water discharge conditions greatly affect the turbine power. Therefore, this study varied the height of the reservoir to change the amount of water discharge and observed its effect on the turbine power of impulse water with alternating blades. The reservoir used in this study had a volume of $0.2 \mathrm{~m}^{3}$, and the outlet diameter was $0.055 \mathrm{~m}$, while the aiming turbine had a diameter of $0.18 \mathrm{~m}$ with a type of impulse with alternating impulse. At the reservoir height of $0 \mathrm{~m}$ the water discharge is $0.008 \mathrm{~m}^{3} / \mathrm{s}$ and produces power of $37.040 \mathrm{~W}$, while when the height of the reservoir is raised at $0.40 \mathrm{~m}$ the power generated by the turbine also increases to 92,236 W. When the reservoir height is raised to $0.89 \mathrm{~m}$ the turbine power is $192,987 \mathrm{~W}$. To conclude, condition shows that the height of the reservoir is directly proportional to the turbine power, it means if the reservoir gets higher,ultimately the turbine power will also increase.

Keywords: impulse, power, reservoir, water discharge

Diterima 17 Juli 2020; direvisi terakhir 27 Agustus 2020; diterbitkan 06 September 2020 


\section{PENDAHULUAN}

Air adalah salah satu Sumber Daya Alam (SDA) yang dapat dimanfaatkan energinya, sehingga dari semula hanya memiliki energi potensial (EP) dapat diubah menjadi energi kinetik (EK), dimana energi kinetik tersebut dapat dimanfaatkan menjadi energi mekanis (EM) pada sistem kerja turbin, sehingga menghasilkan putaran. Dari putaran yang dihasilkan oleh turbin air inilah yang dapat dimanfaatkan sebagai penggerak mula pada Generator.

Turbin air adalah mesin penggerak mula yang kinerjanya sangat dipengaruhi oleh debit air yang bekerja pada turbin air tersebut. Dilihat dari sistem kerjanya, turbin air dibedakan menjadi beberapa jenis, yaitu jenis turbin air impuls dan turbin air reaksi. Dari jenis-jenis turbin air tersebut dapat dikembangkan lagi menjadi berbagai tipe tergantung dari model turbin dan cara kerjanya [1]. Daya turbin air sangat dipengaruhi oleh debit air yang bekerja, dimana debit air tersebut dapat dipengaruhi oleh berbagai macam kondisi, termasuk ketinggian reservoir juga dapat mempengaruhi besar debit air yang sudah tentu berpengaruh terhadap daya turbin [2]. Selama ini energi air yang digunakan adalah air dengan tinggi jatuh dan debit besar. Sementara itu energi air dengan tinggi jatuh dan debit kecil belum banyak dimanfaatkan, padahal di beberapa wilayah Indonesia punya potensi yang cukup besar untuk dikembangkan pembangkit listrik tenaga air dengan tinggi jatuh dan debit kecil (microhydro) [3].

Berdasarkan uraian di atas, maka permasalahan dari penelitian ini adalah bagaimana pengaruh variasi tinggi reservoir terhadap daya turbin impuls dengan sudu bolak-balik. Tujuan yang ingin dicapai dari penelitian ini adalah untuk mengetahui hubungan antara tinggi reservoir dengan: 1). Putaran Turbin, 2). Debit Air, 3). Tekanan Air, dan 4). Daya Turbin.

\section{METODE PENELITIAN}

\section{a. Rancangan Penelitian}

Penelitian ini diawali dengan pembuatan turbin impuls sudu bolak balik berdiameter $0,18 \mathrm{~m}(18 \mathrm{~cm})$ dari bahan pelat baja dengan cara dilas kemudian dilanjutkan dengan membuat rumah turbin, seperti tampak pada gambar 1 di bawah ini.

Pengaruh Variasi Ketinggian Reservoir Terhadap Daya Turbin Air Impuls Dengan Sudu Bolak-Balik

(Kristomus Boimau, Nurhayati, Rima N. Selan, Andi Prasetyo) 


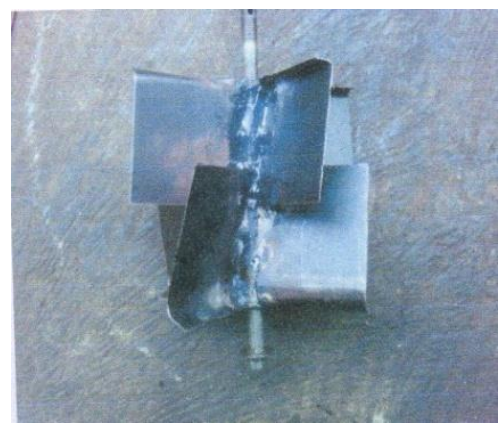

(a)

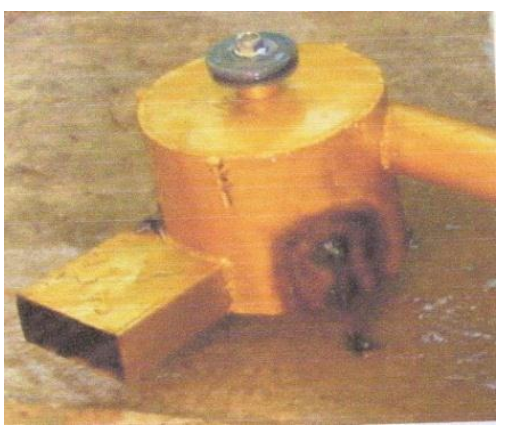

(b)

Gambar 1. (a) Sudu Turbin Impuls, (b) Rumah Turbin

\section{b. Bahan dan Alat Penelitian}

Alat dan bahan yang digunakan dalam penelitian ini, dapat dilihat pada Tabel 1 berikut:

Tabel 1. Alat dan Bahan Penelitian

\begin{tabular}{|c|l|l|}
\hline No & \multicolumn{1}{|c|}{ Alat dan Bahan } & Jumlah/Satuan \\
\hline 1 & $\begin{array}{l}\text { Turbin air Impuls sudu bolak-balik, diameter } \\
0,18 \text { meter }\end{array}$ & 1 buah \\
\hline 2 & Reservoir, Volume $0,2 \mathrm{~m}^{3}$ & 1 buah \\
\hline 3 & Pipa PVC, 2 inch & $4 \mathrm{~m}$ \\
\hline 4 & Sambungan elbow, 2 inch & 2 buah \\
\hline 5 & Tachometer & 1 buah \\
\hline 6 & Wadah ukur, Volume 0,008 $\mathrm{m}^{3}$ & 1 buah \\
\hline 7 & Air & $5 \mathrm{~m}^{3}$ \\
\hline 8 & Stopwatch & $1 \mathrm{buah}$ \\
\hline
\end{tabular}

\section{c. Tahapan Penelitian}

Adapun prosedur pengujiannya dapat diuraikan sebagai berikut:

1. Mengatur air dalam reservoir agar memiliki ketinggian yang tetap, yaitu pada $0,6 \mathrm{~m}$.

2. Setelah air dalam reservoir stabil, kemudian debit air yang keluar dari reservoir diukur menggunakan wadah ukur.

3. Sebelum turbin air dipasang pada pipa yang mengalirkan air dari reservoir, terlebih dahulu debit air yang keluar dari ujung pipa tersebut diukur.

4. Kemudian turbin air impuls sudu bolak-balik dihubungkan pada pipa ke reservoir dimana reservoir inilah yang nanti akan menyuplai air sehingga memutar turbin tersebut. 
5. Reservoir diisi air terus menerus agar terjaga kesetabilan permukaan airnya, sehingga dapat menghasilkan putaran yang konstan pada turbin.

6. Pada saat air mengalir dan memutar turbin, maka putaran turbin tersebut diukur menggunakan tachometer.

7. Setelah putaran turbin diukur, kemudian diukur debit air yang keluar dari turbin

8. Prosedur 1) sampai 8) diulangi beberapa kali dengan merubah ketinggian reservoir pada $0 \mathrm{~m}, 0,4 \mathrm{~m}$, dan $0,89 \mathrm{~m}$ agar dapat menghasilkan variasi data.

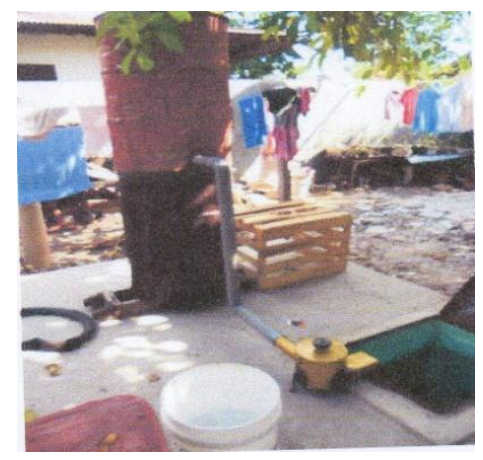

(a)

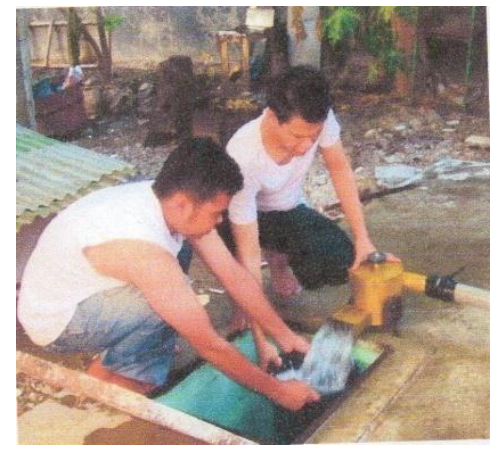

(b)

Gambar 2. (a). Instalasi Reservoir-Pipa PVC-Turbin, (b). Pengambilan Data

\section{HASIL DAN PEMBAHASAN}

\section{a. Kondisi Reservoir}

Kondisi reservoir yang digunakan dalam penelitian ini dapat dilihat pada tabel berikut:

Tabel 2. Kondisi Reservoir

\begin{tabular}{|c|l|c|}
\hline No & \multicolumn{1}{|c|}{ Uraian } & Jumlah/Satuan \\
\hline 1 & Diameter Reservoir (d) & $0,57 \mathrm{~m}$ \\
\hline 2 & Tinggi Air dalam reservoir (h) & $0,60 \mathrm{~m}$ \\
\hline 3 & Diameter Saluran Keluar (D) & $0,055 \mathrm{~m}$ \\
\hline 4 & Debit Air yang keluar dari reservoir (Q) & $0,0075 \mathrm{~m}^{3} / \mathrm{s}$ \\
\hline
\end{tabular}

Pengaruh Variasi Ketinggian Reservoir Terhadap Daya Turbin Air Impuls Dengan Sudu 


\section{b. Data Hasil Pengujian}

Pengujian dilakukan dengan kondisi/data awal seperti pada tabel 2 di atas, kemudian dilakukan variasi terhadap tinggi reservoir. Data Hasil pengujian tersebut berupa debit (Q) dan Putaran Turbin (n) kemudian dihitung menggunakan persamaan sehingga diperoleh Tekanan Air (P) dan Daya Turbin seperti tampak pada tabel di bawah ini.

Tabel 3. Data Hasil Pengujian Turbin Impuls Sudu Bolak-Balik

\begin{tabular}{|c|c|c|c|c|c|c|}
\hline No & $\begin{array}{c}\text { Tinggi } \\
\text { Reservoir, } \\
\mathrm{h}_{2}(\mathrm{~m})\end{array}$ & $\begin{array}{c}\text { Panjang } \\
\text { Pipa, } \mathrm{L} \\
(\mathrm{m})\end{array}$ & $\begin{array}{c}\text { Debit } \\
\text { Air, } \mathrm{Q}_{1} \\
\left(\mathrm{~m}^{3} / \mathrm{s}\right)\end{array}$ & $\begin{array}{c}\text { Tekanan } \\
\text { Air, } \mathrm{P} \\
\left(\mathrm{N} / \mathrm{m}^{2}\right)\end{array}$ & $\begin{array}{c}\text { Putaran, } \\
\mathrm{n}(\mathrm{rpm})\end{array}$ & $\begin{array}{c}\text { Daya Turbin, } \\
\left.\mathrm{P}_{\text {turbin }} \text { (Watt }\right)\end{array}$ \\
\hline 1 & 0,00 & 0,50 & 0,0080 & 4861,82 & 129 & 37,040 \\
\hline 2 & 0,40 & 0,90 & 0,0125 & 8768,942 & 242 & 95,236 \\
\hline 3 & 0,89 & 1,39 & 0,00170 & 13555,17 & 325 & 192,987 \\
\hline
\end{tabular}

\section{c. Pembahasan}

Dari data pada tabel di atas, terlihat bahwa tinggi reservoir berpengaruh terhadap debit, tekanan dan daya turbin. Pada saat pengujian dilakukan, kondisi air di dalam reservoir tetap dijaga dengan cara memompa air ke dalam reservoir sehingga ketinggian air tetap stabil pada level 0,6 m.

1) Hubungan antara Tinggi Reservoir dengan Debit Air

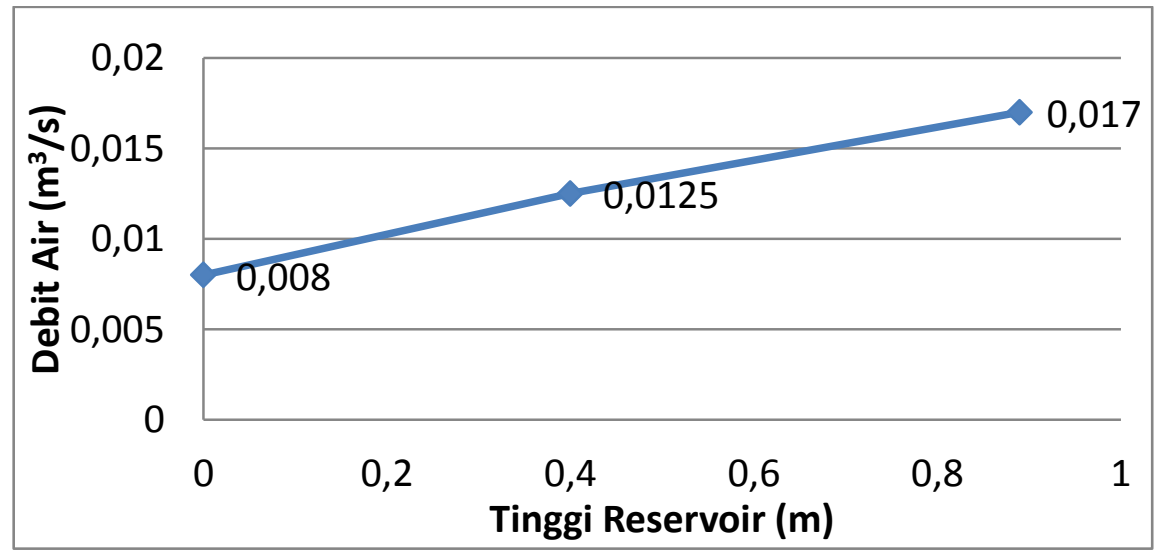

Gambar 3. Hubungan Antara Tinggi Reservoir (m) vs Debit Air (Q)

Dari gambar di atas terlihat bahwa tinggi reservoir mempengaruhi debit air (Q), di mana semakin tinggi reservoir maka debit air pun semakin besar. Hal ini disebabkan oleh laju aliran air yang bertambah akibat perubahan ketinggian. Simpulan ini juga sesuai dengan penelitian terdahulu yang menyatakan bahwa 
semakin tinggi bak penangkap air $(\mathrm{H})$ semakin besar pula debit pada pompa hidram [4].

2) Hubungan antara Tinggi Reservoir dengan Putaran Turbin

Aliran air yang masuk ke dalam rumah turbin menyebakan poros turbin berputar. Untuk mengetahui putaran poros turbin tersebut, maka dilakukan pengukuran dengan alat tachometer. Hasilnya dapat dilihat pada gambar berikut.

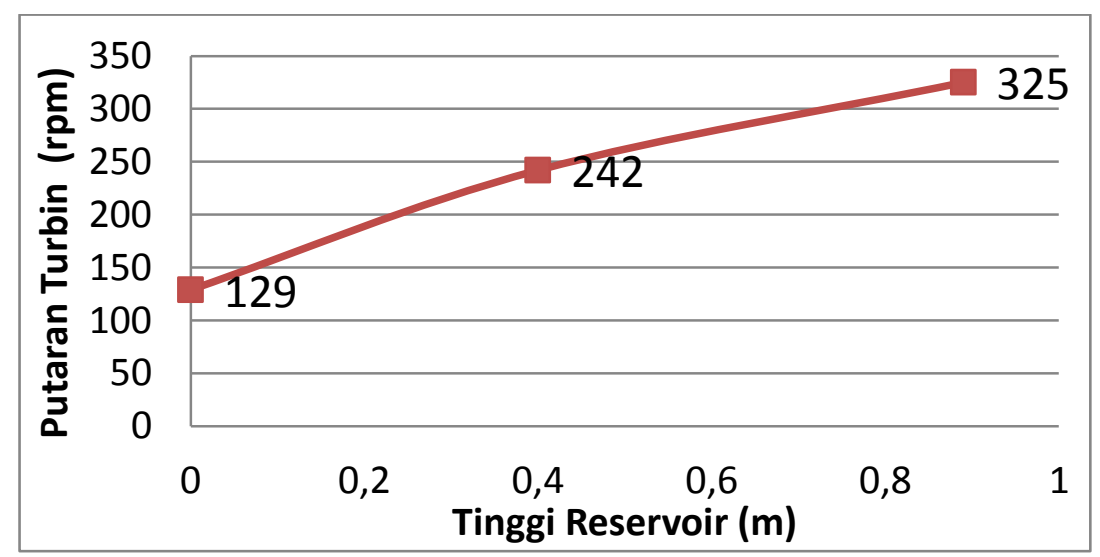

Gambar 4. Hubungan Antara Tinggi Reservoir (m) vs Putaran Turbin (rpm)

Dari gambar di atas, tampak bahwa semakin tinggi letak reservoir maka putaran poros turbin pun cenderung naik. Kondisi ini menunjukkan bahwa tinggi reservoir berbanding lurus dengan putaran poros turbin, sehingga semakin tinggi letak reservoir makan putaran turbin juga akan bertambah. Hal ini disebabkan karena adanya perubahan ketinggian yang berdampak pada meningkatnya energy potensial sehingga energi mekanik pun menjadi bertambah.

3) Hubungan antara Tinggi Reservoir dengan Tekanan Air

Sesuai dengan asas Bernoulli, maka tekanan air pada ujung pipa keluar merupakan gabungan antara energy potensial dan energy kinetic [5]. Hasil perhitungannya dapat dilihat pada gambar di bawah ini. Dari gambar 5 terlihat bahwa tekanan air meningkat seiring dengan bertambahnya tinggi reservoir.

Pengaruh Variasi Ketinggian Reservoir Terhadap Daya Turbin Air Impuls Dengan Sudu Bolak-Balik

(Kristomus Boimau, Nurhayati, Rima N. Selan, Andi Prasetyo) 


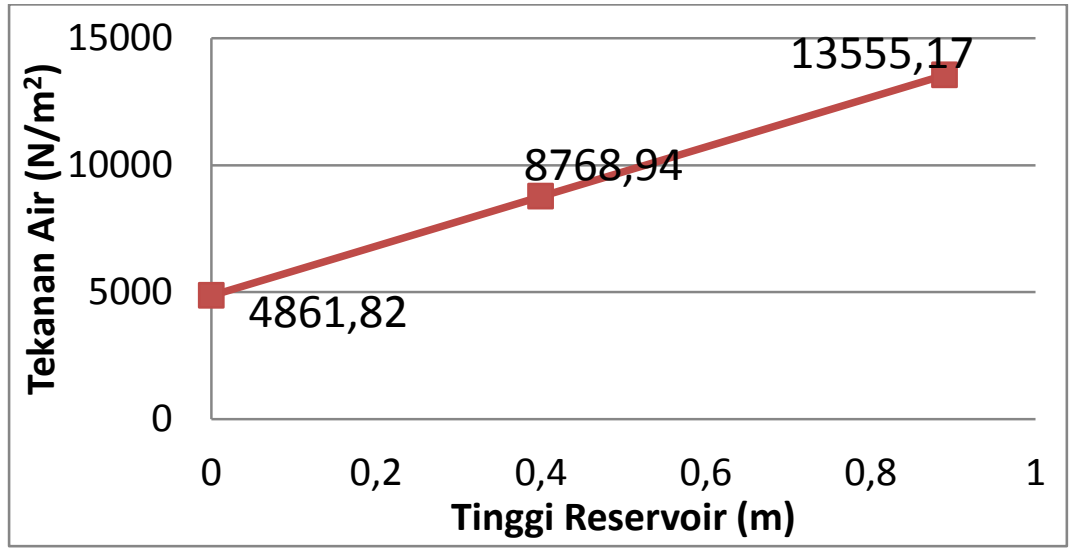

Gambar 5. Hubungan Antara Tinggi Reservoir (m) vs Tekanan Air (N/m²)

4) Hubungan antara Tinggi Reservoir dengan Daya Turbin

Daya turbin diperoleh dengan cara menghitung efisiensi turbin $(\eta)$ terlebih dahulu, kemudian dilanjutkan dengan menghitung daya turbin.

Tabel 4. Data Pengukuran Debit Air (Q)

\begin{tabular}{|c|c|c|c|c|}
\hline No & $\begin{array}{c}\text { Tinggi } \\
\text { Reservoir, } \mathrm{h} \\
(\mathrm{m})\end{array}$ & $\begin{array}{c}\text { Tinggi Jatuh } \\
\text { Air, H }(\mathrm{m})\end{array}$ & $\begin{array}{c}\text { Debit Air, } \\
\text { Sebelum Dipasang } \\
\text { Turbin } \mathrm{Q}_{\text {in }}\left(\mathrm{m}^{3} / \mathrm{s}\right)\end{array}$ & $\begin{array}{c}\text { Debit Air, Setelah } \\
\text { Dipasang Turbin } \\
\mathrm{Q}_{\text {out }}\left(\mathrm{m}^{3} / \mathrm{s}\right)\end{array}$ \\
\hline 1 & 0,00 & 0,60 & 0,0080 & 0,0063 \\
\hline 2 & 0,40 & 1,0 & 0,0125 & 0,0097 \\
\hline 3 & 0,89 & 1,49 & 0,00170 & 0,0132 \\
\hline
\end{tabular}

Dari data pada tabel di atas, maka dapat dihitung efisiensi turbin airnya dan daya turbin. Hasil perhitungan daya turbin dapat dilihat pada gambar berikut.

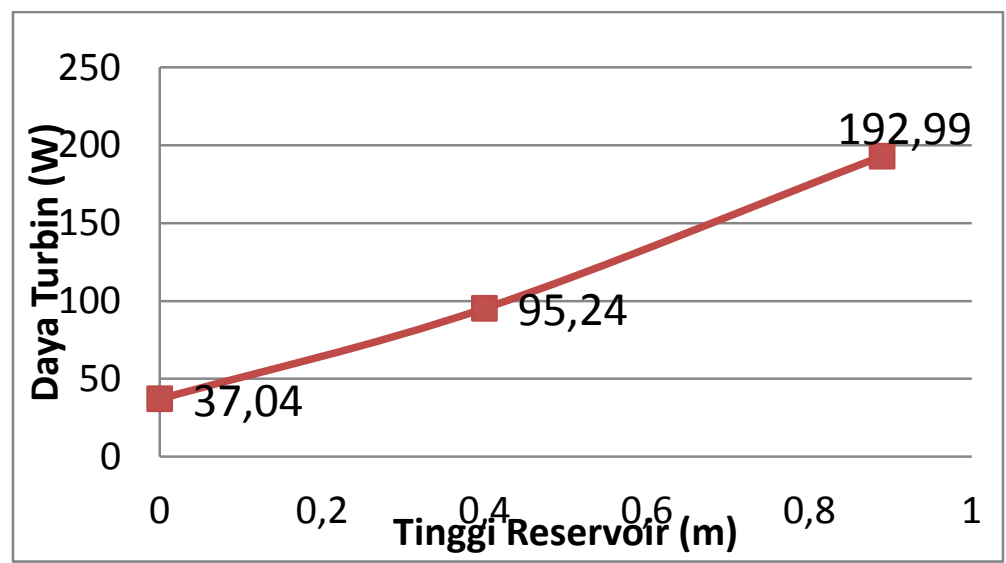

Gambar 6. Hubungan Antara Tinggi Reservoir (m) vs Daya Turbin (W)

Gambar di atas menunjukkan bahwa daya turbin air impuls sudu bolak balik 
yang dihasilkan adalah sebesar 37,04 Watt pada kondisi tinggi reservoir $0 \mathrm{~m}$ atau tinggi jatuh air $(\mathrm{H}) 0.6$ meter dari permukaan tanah. Selanjutnya jika tinggi reservoir dinaikan menjadi $0,4 \mathrm{~m}$ atau tinggi jatuh air $1 \mathrm{~m}$ maka daya yang dihasilkan adalah 95,236 Watt, sedangkan daya turbin naik menjadi 192,99 Watt jika tinggi reservoirnya menjadi $0,89 \mathrm{~m}$.

\section{SIMPULAN}

Dari pembahasan tersebut, dapat disimpulkan bahwa:

1. Semakin tinggi reservoir, maka semakin besar tekanan dan debit air yang dihasilkan sehingga daya turbin yang dihasilkan pun semakin bertambah.

2. Turbin Air impuls sudu bolak balik dapat menghasilkan daya sebesar 192,99 Watt dengan tinggi jatuh air 1,49 meter.

\section{SARAN}

Perlu dilakukan penelitain lebih lanjut tentang pengaruh ketinggian reservoir terhadap daya turbin air dengan variabel yang lain misalkan dengan spesifikasi sudu yang berbeda, ketinggian reservoir, dan ketinggian air jatuh yang lebih variatif.

\section{DAFTAR PUSTAKA}

[1] W. Arismunandar, Penggerak Mula Turbin, Bandung: ITB, 1982

[2] A. Muliawan and A. Yani, Analisis Daya Dan Efisiensi Turbin Air Kinetis Akibat Perubahan Putaran Runner. Journal of Sainstek, vol. 8, no.1, pp: 1-9, 2016

[3] M. Triono, Pemodelan Turbin Cross-Flow Untuk Diaplikasikan Pada Sumber Air Dengan Tinggi Jatuh dan Debit Kecil. Jurnal Nutrino, vol. 4, no. 2, 2012

[4] G.P. Utomo, Supardi, and E. Santoso, Analisa Pengaruh Tinggi Jatuhan Air Terhadap Head Pompa Hidram. Jurnal Pengabdian Lppm Untag Surabaya. vol. 1, no. 2, 2015

[5] L. Streeter, Mekanika Fluida Edisi 8 Jilid 1, Jakarta: Erlangga, 1992

Pengaruh Variasi Ketinggian Reservoir Terhadap Daya Turbin Air Impuls Dengan Sudu Bolak-Balik

(Kristomus Boimau, Nurhayati, Rima N. Selan, Andi Prasetyo) 